\title{
Hypoxia inducible factor- 1 alpha expression is increased in infected positive HPV16 DNA oral squamous cell carcinoma and positively associated with HPV16 E7 oncoprotein
}

Vito Rodolico ${ }^{*}$, Walter Arancio ${ }^{1}$, Marco C Amato ${ }^{2}$, Francesco Aragona $^{1}$, Francesco Cappello ${ }^{3}$, Olga Di Fede ${ }^{4}$, Giuseppe Pannone $e^{5}$ and Giuseppina Campisi ${ }^{4}$

\begin{abstract}
Background: There is increasing evidence for the role of High Risk (HR) Human PapillomaVirus (HPV) in the pathogenesis of Oral Squamous Cell Carcinoma (OSCC). The E6 and E7 oncogenes from HR HPVs are responsible for the deregulation of p53 and pRB proteins involved in cell cycle and apoptotic pathways. In cell lines experiments, the HPV E7 protein seems to be able to enhance Hypoxia Inducible Factor-1 alpha (HIF-1 $\alpha$ ) activity, normally involved in the response to hypoxia and able to enhance angiogenesis.

Results: We studied tumor specimens from 62 OSCC; a higher prevalence of tumors in TNM stage II and also in PT2 class between OSCC infected positive HPV16 DNA than non-infected ones was observed. HIF-1 $\alpha$ positivity was detected throughout the analysed fields, not associated with areas of necrosis and also observed in cells immediately adjacent to blood vessels. A significant increase in mean values of the HIF-1 $\alpha$ labeling indexes was observed for PT1-T2, as well for stage I-II, in the infected positive HPV16 DNA tumors than non-infected ones. HIF$1 \alpha$ and HPV16 E7 labeling indexes showed a significantly positive correlation which suggested a positive association between HPV16 E7 and HIF-1 $\alpha$ expression.

Conclusions: In our specimens HIF-1 $\alpha$ immunoreactivity hints for an $\mathrm{O}_{2}$-independent regulatory mechanism in infected positive HPV16 DNA tumors, especially for PT1-T2 and stage I-II tumors, suggesting a very early involvement in the development of HPV-induced OSCC. HIF-1 $\alpha$ and HPV16 E7 labeling indexes suggest also a positive association between the two proteins in infected positive HPV16 DNA OSCC.
\end{abstract}

Keywords: Oral Squamous Cell Carcinoma, Hif-1a, HPV, HPV16, E7

\section{Background}

Nowadays there is increasing evidence for the role of high risk (HR) Human PapillomaVirus (HPV) in the pathogenesis of Oral Squamous Cell Carcinoma (OSCC) [1-7], till to consider HPV positive (HPV+) OSCC as a distinct clinicopathological entity with a different outcome in comparison with HPV negative (HPV-) OSCC [2,6,8-11]. The HR types HPV16, 18, 31 and others, are frequently found in cervical cancers and have been

\footnotetext{
* Correspondence: vito.rodolico@unipa.it

'Department of Sciences for Health Promotion, Section of Anatomic

Pathology, University of Palermo, Palermo, Italy

Full list of author information is available at the end of the article
}

found to be risk factors also for OSCC, independently from alcohol and tobacco use [2,12-16]. HPV16, the most common HR HPV type detected in biopsies from women with cervical squamous cell carcinoma (55\%) $[17,18]$, was also the most common type detected in OSCC (16\%), accounted for $68.2 \%$ of all HPV+ OSCC $[19,20]$.

The E6 and E7 oncogenes from HR HPVs are responsible for maintaining differentiating cells active in cell cycling and are able to transform both cervical and upper aero-digestive tract epithelia via expression of the viral oncoproteins E6 and E7 and the following deregulation of cell cycle and apoptotic pathways [21,22].

\section{Biomed Central}


These 2 proteins promote the degradation of cellular tumor suppressors: p53 in the case of E6 and pRb family members in the case of E7. Binding and degradation of pRb family members by E7 results in the release of E2F transcription factors that in turn drive the cell into $S$ phase. The abrogation of $\mathrm{pRb}$ function by HR E7 proteins induces a stress response leading to an elevated activity of p53, which can in turn induce apoptosis [23]. But the high-risk E6 proteins degrade p53, thus preventing apoptosis and allowing continued proliferation. In addition to these well-known activities, both proteins have a wide range of other targets [23], and the extent to which these additional interactions contribute to $\mathrm{HPV}$-associated carcinogenesis is not fully understood. Among the additional factors bound by E7 are histone deacetylases (HDAC), which catalyze the deacetylation of histones and other transcriptional regulatory proteins [24].

One important characteristic of both benign and malignant lesions is the ability to promote angiogenesis, which allows a growing lesion to access nutrients and oxygen for growth [25]. Angiogenesis is mainly triggered by hypoxia or reduced tissue oxygen levels. The cellular response to hypoxia is primarily regulated through the activity of the transcription factor Hypoxia-Inducible Factor-1 (HIF-1) [26,27]. HIF-1 consists of a heterodimer of two proteins (HIF-1 $\alpha$ and HIF-1 $\beta$ ) which mediates the transcription activation of several genes involved in stress response [28]; under normal oxygen conditions (normoxia), the HIF- $1 \alpha$ subunit has a very short half-life due to oxygen-dependent hydroxylation and consequent degradation through the von HippelLindau (VHL)/proteasome pathway; under hypoxic conditions, reduced oxygen levels result in the accumulation of HIF-1 $\alpha$, which translocates to the nucleus and leads to the accumulation of functional HIF-1 Transcription Factors that in turn activate the expression of HIF-1 target genes, including a range of proangiogenic factors and enzymes that favor glycolytic over aerobic metabolism [27]. In addition to this hypoxia-dependent stabilization system, a range of other post translational modifications and signaling pathways, also affect HIF-1 $\alpha$ synthesis, stability, and activity such as the p53, p300/ CBP, and several HDACs [29-31].

Recent studies indicate that, in cell lines experiments, the HPV E7 protein is responsible for enhanced HIF-1 $\alpha$ activity and enhances HIF-1 dependent transcription by inducing the dissociation of HDACs from HIF-1 $\alpha$ [32].

The aim of this study was to examine the HIF-1 $\alpha$ protein expression in OSCC to test the hypothesis that HPV E7 protein may influence HIF- $1 \alpha$ expression in OSCC infected positive for HPV16 DNA.

\section{Results}

\section{Characteristics of the Study Population}

We studied tumor specimens from 62 OSCC; clinicopathological characteristics for non-infected (Group I) vs. infected positive HPV16 DNA tumors (Group II) are detailed in Table 1. The two groups of tumors did not differ statistically significantly with regard to patient age at diagnosis, sex, site, histological grading; instead, statistically significant differences were found regarding TNM stage $(p<.001)$ and tumor size $(p<$ $.001)$ : in particular a higher prevalence of tumors in TNM stage II between OSCC infected positive HPV16 DNA (76.9\%) than non-infected ones $(23.1 \%)$ was observed and refining the components of TNM staging, also in pT2 class (73.3\% infected positive HPV16 DNA tumors).

Table 1 Comparison of clinico-pathological parameters in HPV- DNA (group I) and HPV16+ DNA (group II) oral squamous cell carcinomas

\begin{tabular}{|c|c|c|c|c|c|}
\hline Parameters & $\begin{array}{l}\text { Group I } \\
\text { (HPV-) } \\
(\%)\end{array}$ & n.39 & $\begin{array}{l}\text { Group II } \\
\text { (HPV16+) } \\
(\%)\end{array}$ & n.23 & $\underset{\text { value }^{*}}{p}$ \\
\hline \multicolumn{6}{|l|}{ Age at diagnosis, year } \\
\hline$<53$ & $(10)$ & 4 & (4) & 1 & \\
\hline $53-73$ & $(54)$ & 21 & $(70)$ & 16 & \\
\hline$>73$ & $(36)$ & 14 & $(26)$ & 6 & N.S \\
\hline \multicolumn{6}{|l|}{ Sex } \\
\hline Female & $(46)$ & 18 & $(43)$ & 10 & \\
\hline Male & $(54)$ & 21 & $(57)$ & 13 & N.S. \\
\hline \multicolumn{6}{|l|}{ Site of primary tumor } \\
\hline Tongue & $(46)$ & 18 & $(48)$ & 11 & \\
\hline Buccal Mucosa & $(26)$ & 10 & $(22)$ & 5 & \\
\hline Alveolar Ridge Mucosa & $(18)$ & 7 & $(17)$ & 4 & \\
\hline Palate & $(10)$ & 4 & $(13)$ & 3 & N.S. \\
\hline \multicolumn{6}{|l|}{ Tumor Histological Grade } \\
\hline Well (G1) & $(57)$ & 22 & $(65)$ & 15 & \\
\hline Moderate (G2) & $(28)$ & 11 & $(26)$ & 6 & \\
\hline Poor (G3) & $(15)$ & 6 & (9) & 2 & N.S. \\
\hline \multicolumn{6}{|l|}{ TNM Stage } \\
\hline 1 & $(64)$ & 25 & $(22)$ & 5 & \\
\hline$\|$ & $(8)$ & 3 & $(44)$ & 10 & \\
\hline III & (13) & 5 & $(30)$ & 7 & \\
\hline IV & $(15)$ & 6 & (4) & 1 & $<.001$ \\
\hline \multicolumn{6}{|l|}{ pT } \\
\hline 1 & (64) & 25 & $(22)$ & 5 & \\
\hline 2 & $(10)$ & 4 & $(48)$ & 11 & \\
\hline 3 & $(10)$ & 4 & $(26)$ & 6 & \\
\hline 4 & (16) & 6 & (4) & 1 & $<.001$ \\
\hline
\end{tabular}

* Chi-square test and Fisher's exact test; statistical results were considered significant for $p$ values $<.05$ (N.S. indicates not significant) 
Immunohistochemical analysis of HPV16 E7 oncoprotein It was analyzed whether high-risk HPV16 E7 oncoprotein were detectable by immunohistochemical analysis. No HPV16 E7 oncoprotein staining could be detected in the 39 specimens from tumors negative for HPV DNA as expected; instead in the 23 tumors positive for HPV16 DNA, the affinity-purified monoclonal antiHPV16 E7 antibody recognized almost all epithelial cells within the tumor islets (Figure 1A, B) but did not stain any cells in the adjacent connective tissues. Dysplastic tumor cells in precancerous squamous epithelium adjacent to the cancerous tumor islets in the same section were also positively stained. Keratinocytes in areas of non-neoplastic squamous epithelium were not stained. In keeping with a previous study [33], these findings suggest that E7 can be considered as a marker for premalignant intraepithelial lesions. Whereas all HPV16 DNA positive carcinomas stained positive for E7, a more detailed analysis revealed strong variations in E7 oncoprotein expression levels with labeling indexes ranged from $32.6 \%$ to $100 \%$ (mean $77.15 \pm 25.01$ ). Because there was only one case in pT4 class and in stage IV, we chose to dichotomize size as pT3 and pT4 vs. pT1 and pT2 as well stage TNM III and IV vs. I and II. In the pT1-T2 group, E7 oncoprotein labeling indexes ranged from $32.6 \%$ to $95.4 \%$ (mean $68.73 \pm 19.89$ ); in the pT3T4 group, E7 oncoprotein labeling indexes ranged from $83,8 \%$ to $100 \%$ (mean $96.4 \pm 6.01$ ); these differences

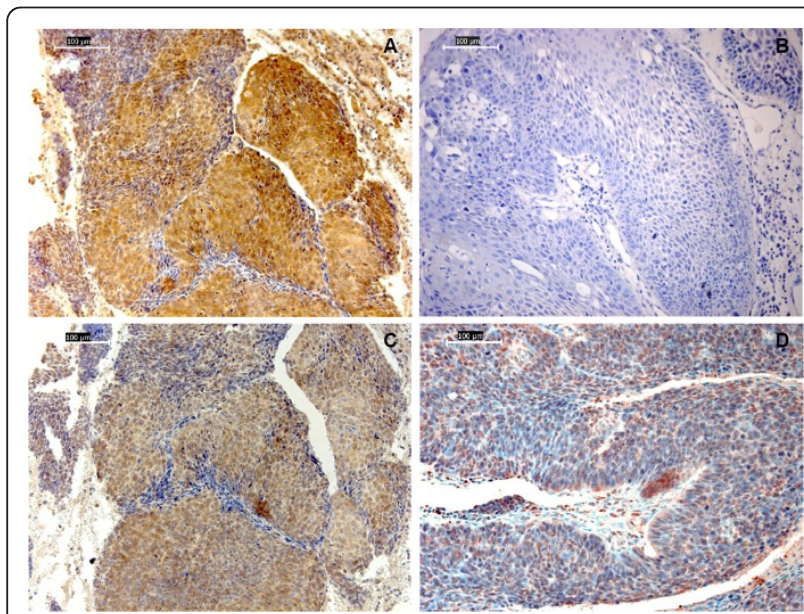

Figure 1 Representative images of HPV16 E7 oncoprotein and HIF-1 $\alpha$ protein immunostaining of paraffin sections from oral squamous cell carcinomas. A) Tumor positive for HPV16 DNA with almost all epithelial tumor cells stained positive for E7; B) tumor negative for HPV DNA with no HPV16 E7 oncoprotein staining; C) Consecutive section of the same specimen of tumor positive for HPV16 DNA represented in "A)", stained with the anti-HIF-1 $\alpha$ antibody: uniform location of immunoreactivity for HIF- $1 \alpha$ and HPV16 E7 on the same tumor; D) weak expression for HIF-1 $\alpha$ in tumor cells of tumor negative for HPV DNA (magnifications $\times 200$; scale bars $100 \mu \mathrm{m})$. proved to be significant $(p<.001)$ (Figure 2$)$. Similar results were also obtained for stages groups [Stage I-II labeling indexes from $32.6 \%$ to $96.6 \%$ (mean $66.96 \pm$ 19.23); Stage III-IV from $83.8 \%$ to $100 \%$ (mean $96.27 \pm$ 5.57); $p<.001]$. No significant differences were found for age, sex, site or histological grading (data not shown).

\section{HIF-1 $\alpha$ expression is increased in infected positive HPV16} DNA tumors

Immunohistochemical staining was also performed to identify the presence of the HIF- $1 \alpha$ protein; immunoreaction was revealed in all cases but two of the noninfected group, both of them were very small tumors (pT1 of mm 4 and mm 5, TNM stage I) of the tongue.

In our specimens HIF- $1 \alpha$ positivity was detected throughout the analysed fields, not associated with areas of necrosis and also observed in cells immediately adjacent to blood vessels. Adjacent non-neoplastic tissue, the stromal and normal cells did not show immunoreactivity for HIF-1 $\alpha$. In the 62 tumor's specimens investigated, the labeling indexes ranged from $0 \%$ to $94.5 \%$ (mean $45.26 \pm 26.6$ ). No significant differences for mean value of HIF-1 $\alpha$ labeling indexes were found for age, sex, site or histological grading; however the labeling indexes showed a significant increase in mean values for pT1-T2 tumors vs. pT3-T4 (33.02 \pm 19.66 vs. $77.65 \pm$ 9.93; $p=.015)$, as well for Stage I-II vs. Stage III-IV $(31.41 \pm 18.53$ vs. $76.6 \pm 10.12 ; p=.03)$.

Generally, immunoreactivity for HIF-1 $\alpha$ was detected with intense cytoplasmatic and nuclear positivity in tumor cells of cases with positive HPV16 DNA (Group

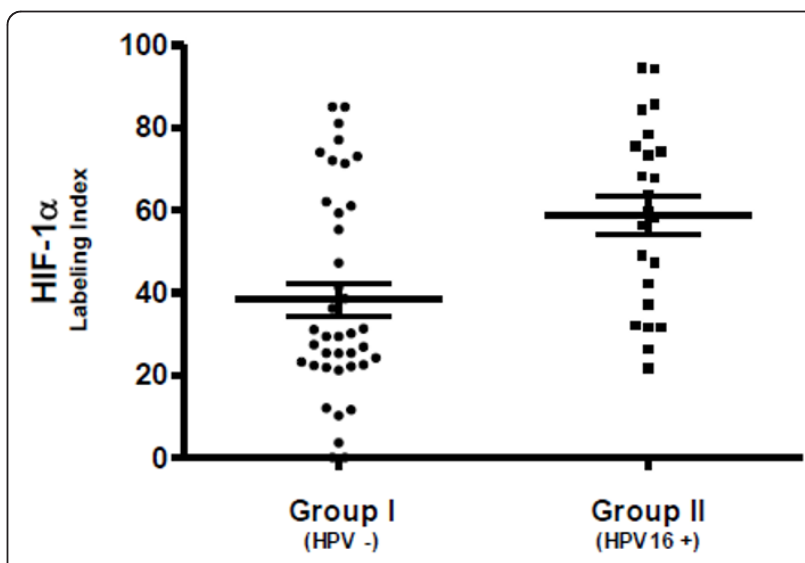

Figure 2 Labeling indexes immunoreactivity for HIF-1 $\alpha$ in paraffin sections from oral squamous cell carcinomas. A lower HIF-1 $\alpha$ protein expression was observed in tumors negative for HPV DNA in comparison with those positive for HPV16 DNA (37.24 \pm 25.95 vs. $58.85 \pm 22.17 ; p<.001)$. Differences were analyzed by the Mann-Whitney test; statistical results were considered significant for $p$ values $<.05$. 
II) (Figure 1C), whereas a weak cytoplasmatic expression was found in tumor cells of the non-infected group (Group I) (Figure 1D), similar to the one found in some of the islet of precancerous squamous epithelium adjacent to the infected positive HPV16 DNA tumors (Group II).

In the positive HPV16 DNA tumors (Group II), the HIF- $1 \alpha$ labeling indexes ranged from $21.7 \%$ to $94.5 \%$ (mean $58.85 \pm 22.17$ ), while in the non-infected group (Group I), ranged from $0 \%$ to $85 \%$ (mean $37.24 \pm$ $25.95)$; these differences proved to be significant $(p<$ .001) (Figure 2).

On examining the mean values of the HIF-1 $\alpha$ labeling indexes between Group II and Group I, significant differences were not found for age, sex, site or histological grading; however, statistical analysis demonstrated for pT1-T2 tumors a significant increase in mean values of the HIF-1 $\alpha$ labeling indexes in the infected positive HPV16 DNA tumors $(48.31 \pm 17.14)$ than non-infected tumors [(24.59 \pm 15.58$) ; p<.001]$, as well for stage I-II tumors [(46.59 \pm 16.24 mean value of the HIF-1 $\alpha$ labeling indexes in Group II; $23.28 \pm 14.17$ mean values in Group I); $p<.001]$. The same analysis for pT3-T4 group of tumors $[(82.94 \pm 9.77$ mean values of the HIF$1 \alpha$ labeling indexes in Group II; $73.96 \pm 8.64$ mean values in Group I); $p=.07$ ] as well for stage III-IV $[(81.85 \pm 9.56$ mean values of the HIF- $1 \alpha$ labeling indexes in Group II; $72.78 \pm 9.08$ mean values in Group I); $p=.05$ ] did not showed significant differences in mean values of the HIF-1 $\alpha$ labeling indexes between Group II and Group I (Figure 3).

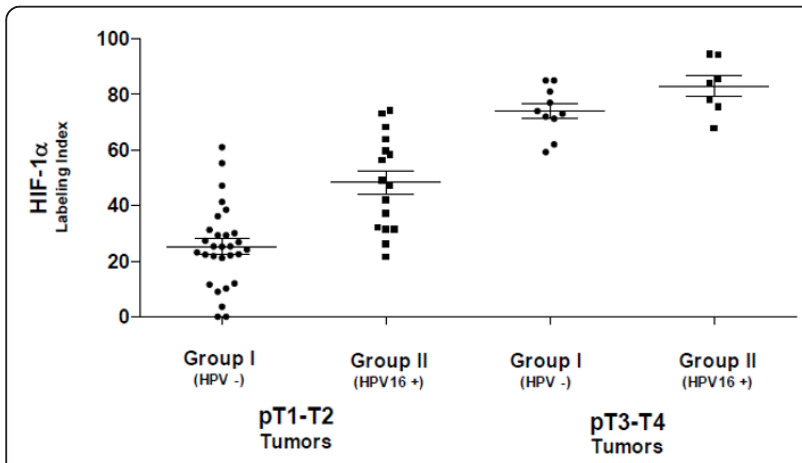

Figure 3 Labeling indexes immunoreactivity for HIF-1 $\alpha$ in pT1T2 and pT3-T4 oral squamous cell carcinomas. PT1-T2 tumors showed a significant increase in mean values of the HIF-1 $\alpha$ labeling indexes in infected positive HPV16 DNA tumors than non-infected tumors (48.31 \pm 17.14 vs. $24.59 \pm 15.58 ; p<.001)$; pT3-T4 tumors did not showed significant differences in mean values of the HIF-1 $\alpha$ labeling indexes between infected positive HPV16 DNA tumors and non-infected tumors $(82.94 \pm 9.77$ vs. $73.96 \pm 8.64 ; p=.07)$ Differences were analyzed by the Mann-Whitney test; statistical results were considered significant for $p$ values $<.05$.
Interestingly, HIF-1 $\alpha$ and HPV16 E7 immunoreactivity were uniform in location on the same tumor (Figure 1A and $1 \mathrm{C}$ ), and their labeling indexes showed a significantly positive correlation (Rho $=.512 ; p<.001$ ), which suggested a positive association between HPV16 E7 and HIF-1 $\alpha$ expression (Figure 4). A more detailed analysis showed a stronger positive association between the two proteins in pT1-T2 group than in pT3-T4 [(pT1-T2 tumors: Rho $=.669 ; p<.001)(\mathrm{pT} 3-\mathrm{T} 4:$ Rho $=.494 ; p=$ $.04)]$ and stage I-II tumors than stage III-IV [(stage I-II tumors: Rho $=.684 ; p<.001)$ (III-IV: Rho $=.510 ; p=$ $.02)]$.

\section{Discussion}

Several studies have investigated the role of HPV in oral carcinogenesis, confirming that HPV plays a role in oral carcinogenesis and HPV cancers are specific type of tumors with numerous important differences reported in typology of risk patient (generally, never married younger males, < 40 yrs.), histological grading (well differentiated cancer), histotype (possible but not necessary basaloid appearance with a characteristic faster growing) and clinical outcome in term of overall survival (patients with HPV-positive OSCC had a lower risk of dying and a lower risk of recurrence than HPV-negative OSCC patients) [34-37]. However, the protective mechanism by which HPV infection improves the overall survival and prognosis in oral cancer is not yet clearly understood. HPV16, the most common HR HPV type detected in biopsies from women with cervical SCC $(55 \%)[17,18]$, was also the most common type detected in OSCC (16\%), accounted for $68.2 \%$ of all HPV+ OSCC $[19,20]$.

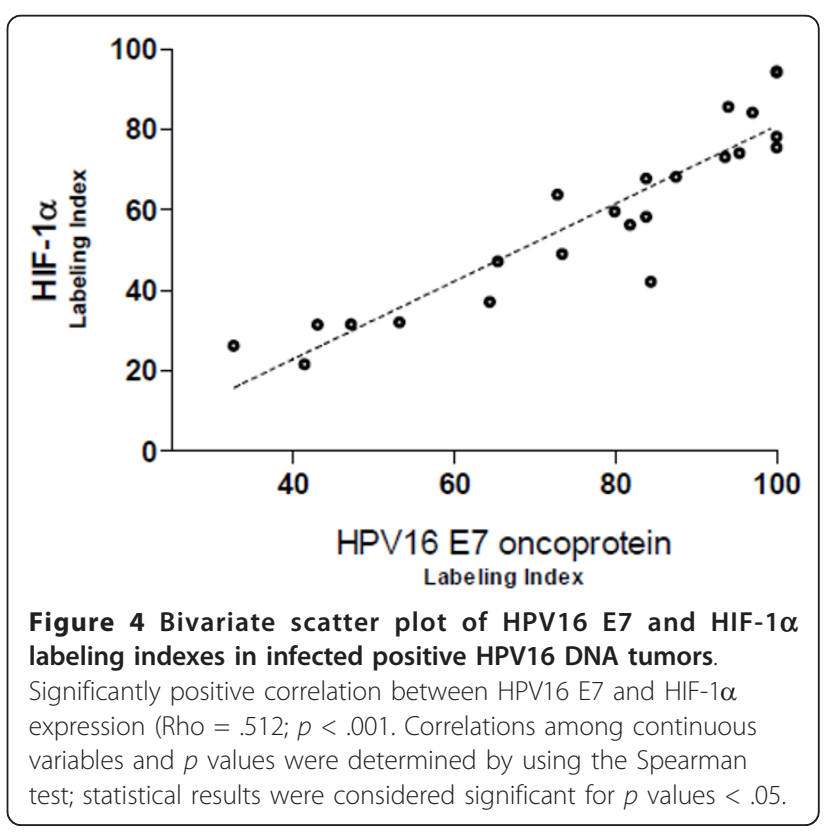


In our own study, a higher prevalence of OSCC in TNM stage II was found among infected positive HPV16 DNA tumors than non-infected tumor ones and, refining better the components of TNM staging, a higher prevalence was also found for HPV status in OSCC pT2. The prevalence of OSCC in stage II and pT2 class positively infected by HPV16 could be reasonably explained by their faster growing and higher proliferative activity than negative HPV ones, as also observed in studies investigating markers of proliferation, such as the proliferating cell nuclear antigen (PCNA) [38].

The HR HPV types that infect the genital mucosa typically last from 12-18 months and are eventually cleared by the immune system [39]. Approximately $10 \%$ of women fail to clear HPV infections, resulting in longterm persistent infection [40]. Maintenance of the viral episome in basal cells is the basic function of the early, or maintenance, phase of the viral life cycle. E6, E7, E1 and E2 are each necessary for continued episomal maintenance of whole genomes in cell culture [41]. HPVs exert their oncogenic role after DNA integration, gene expression of E5, E6 and E7 loci and p53/pRb host proteins suppression, leading to increased cell proliferation and contributing to carcinogenesis $[42,43]$.

In the present study, the detection of the E7 oncoprotein always coincided with the presence of an invasive OSCC positive for HPV16 DNA; when we compared the E7 oncoprotein expression with the clinico-pathologic characteristics of these lesions, we found an association between E7 oncoprotein expression and TNM stage and tumor size. There is strong evidence that expression of the E7 oncogene is necessary for the induction and maintenance of the transformed phenotype [44]; however, the role of the E7 oncoprotein in OSCC has remained elusive. In this study, we analyzed for the first time the high-risk E7 oncoprotein expression in OSCC infected positive HPV16 DNA and we report the presence of high-risk HPV oncoprotein in all of these OSCC cancer specimens. These findings indicate that the high-risk E7 oncoproteins of HPV16 is expressed continuously in invasive HPV16 DNA positive OSCC.

As HPVs lesions persist they become larger and exhibit increased requirements for nutrients. In proliferating lesions there is competition between cells for nutrients and oxygen, and this can result in arrest of cellular proliferation or even cell death. HPV lesions overcome this constraint by promoting angiogenesis [45-47]. In many cancers, angiogenesis occurs only late in tumor progression, but increased vascular density and production of angiogenic factors is a very early event in the development of HPV-induced pre-malignant lesions and cervical cancers $[46,47]$. Furthermore, several studies have reported that HPV gene products can induce the production of angiogenic factors from infected cells [48-51].

Transient transfection of E6 and E7 expression vectors into cervical cancer cell lines was reported to induce higher HIF-1 $\alpha$ levels under normoxic conditions [48]. Others studies indicate that cells containing complete HPV31 genomes showed enhanced levels of HIF-1 $\alpha$ upon treatment with the hypoxia mimic deferoxamine mesylate (DFO), which resulted from protein stabilization and lead to increases in some but not all downstream effectors of the hypoxic response, suggesting that HPV specifically manipulates aspects of the cellular hypoxic response; both HPV E6 and E7 were able independently to enhance induction of HIF-1 $\alpha$ upon DFO treatment [52]. A recent study indicate that, in cell lines experiments, the HPV E7 protein is responsible for enhanced HIF- $1 \alpha$ activity and enhances HIF-1 dependent transcription by inducing the dissociation of HDACs from HIF-1 $\alpha$ [24].

In our specimens HIF-1 $\alpha$ positivity was detected throughout the analysed fields, not associated with areas of necrosis and also observed in cells immediately adjacent to blood vessels, suggesting an $\mathrm{O}_{2}$-independent regulatory mechanism. Generally, in infected positive HPV16 DNA tumors we found increased expression for HIF-1 $\alpha$, especially for stage I-II and pT1-pT2 tumors, suggesting a very early event in the development of HPV-induced OSCC. We also observed that HIF- $1 \alpha$ and HPV16 E7 immunoreactivity were uniform on the same specimens with a positive correlation of their labeling indexes which suggests a positive association between HPV16 E7 and HIF-1 $\alpha$ expression in infected positive HPV16 DNA OSCC.

\section{Conclusions}

In our specimens HIF- $1 \alpha$ immunoreactivity hints for an $\mathrm{O}_{2}$-independent regulatory mechanism in infected positive HPV16 DNA tumors, especially for pT1-T2 and stage I-II tumors, suggesting a very early involvement in the development of HPV-induced OSCC. HIF- $1 \alpha$ and HPV16 E7 labeling indexes suggest also a positive association between the two proteins in infected positive HPV16 DNA OSCC. Finally, it may also be extremely interesting to investigate an effective way to inhibit tumor progression in early infected positive HPV16 DNA OSCCs by blocking the activity of HIF-1.

\section{Methods}

\section{Patients and Tumor Specimens}

The study population was composed of 62 randomly selected patients who underwent surgical resection for histologically diagnosed OSCC; tissue samples taken from the subjects and stored in the archives of the 
Department of Sciences for Health Promotion, Section of Anatomic Pathology, University of Palermo, provided adequate histological material. Twenty-three of the 62 OSCC were positive for HPV DNA; all $23 \mathrm{HPV}$ DNA positive tumors contained HPV16 DNA. Forty-seven cases, 39 negative for HPV DNA and 8 positive for HPV16 DNA, were selected from our previous work [53]; others HPV DNA positive samples were excluded from the study because specific monoclonal antibodies to HPV E7 protein for immunohistochemistry was available only for HPV16 type. The 8 HPV16 positive cases from our previous study were retest to assert their HPV16 positivity via PCR method from paraffin embedded archived material. The remaining 15 cases positive for HPV16 DNA were added from PCR analysis on other archival material.

The mean age of the 62 patients was 62.14 years (SD \pm 9.42 ), range (29-81); males 20 (35.7\%), females 36 (64.3\%). Out of 62 OSCCs, 29 were localised on the tongue, 15 on buccal mucosa, 11 on alveolar ridge mucosa and 7 on the palate.

Informed consent was obtained from all patients and the IRB of the University of Palermo, Italy, approved the study.

\section{Histological analysis}

Microscopic evaluation was performed by one oral pathologist (VR), who confirmed OSCC diagnosis and also determined the score of Histological Grading (HG). The World Health Organization criteria [54] were used as follows: grade 1 (G1), well differentiated; grade 2 (G2), moderately differentiated and grade 3 (G3), poorly differentiated. Grade is dependent on the degree of prickle formation, keratinization, and overall resemblance of carcinoma to normal squamous epithelium.

\section{PCR and sequencing analysis}

Each formalin-fixed, paraffin-embedded tissue sample was processed as described in[55] to obtain DNA samples to be used in the following PCR analysis. All samples were checked for DNA quality by amplification of the human $\beta$-globin gene using the couple of primers PCO3+ (5'CTTCTGACACAACTGTGTTCACTAGC3') and PCO4+ (5'TCACCGCAACTTCATCCACGTTCACC3') and tested in duplicate. Three types of controls were included in each reaction series: blank control, HPV-negative cells Wi as negative control and HPV18 DNA-positive HeLa cells, in dilutions from 20,000-50,000 down to 2-5 HPV-DNA copies, as positive control. HPV-DNA was amplified in a $n \mathrm{PCR}$ assay [MY09 (CGTCC(AC)A(AG)(AG)GGA(AT)ACTGATC) - MY11 (GC(AC)CAGGG(AT)CATAA(CT)AATGG) degenerated primer pair in combination with GP5 (5’TTTGTTACTGTGGTAGATACTAC3') - GP6
(5'GAAAAATAAACTGTAAATCATATTC3') primer pair] as previously described [56], and amplifications were performed in a DNA thermal cycler (Mastercycler gradient, Eppendorf, Hamburg, Germany); amplification products were analyzed in 1\% agarose gel.

HPV genotyping was based on direct sequencing of MY- or MY/GP-PCR fragments [56]. Amplification products were purified by Microcon YM-100 (Amicon, Millipore); the sequence of both DNA strands was determined by the BigDye Ready Reaction Kit (PerkinElmer Applied Biosystem, Foster City, Calif.) in the automatic sequencer ABI Prism 310 Analyzer (PerkinElmer Applied Biosystem). Alignments were obtained from the GenBank on-line BLAST server and HPV sequences were downloaded from the HPV database http://hpv-web.lanl.gov.

\section{Immunohistochemistry}

Tissue samples were fixed in $10 \%$ buffered formalin, dehydrated in ethanol and paraffin-embedded according to the routine technique. Immunohistochemical analyses were performed on 3- $\mu$ m-thick paraffin-embedded sections of tumors as routine procedure as described in [57]. Briefly, sections were subsequently exposed to either mouse monoclonal anti HPV16 E7 oncoprotein (Invitrogen Corporation, Camarillo, CA, USA), dilution $1: 50$, for 2 hours at $25^{\circ} \mathrm{C}$ or rabbit polyclonal anti-HIF$1 \alpha$ (Novus Biologicals, Littleton, Co, USA), dilution $1: 100$, for 1 hour at $25^{\circ} \mathrm{C}$, or unconjugated rabbit immunoglobulins (negative control) for 1 hour at $25^{\circ} \mathrm{C}$. Staining was detected using Novolink Polymer Detection System, (Novocastra Laboratories, Newcastle Upon Tyne, UK) according to manufacturer's instructions and counterstained with aqueous hematoxylin.

\section{Immunohistochemical evaluation}

For the evaluation of HPV16 E7 oncoprotein and HIF$1 \alpha$ immunoreactions, tissues were examined for evidence of staining with the aid of the NIH ImageJ software http://rsbweb.nih.gov/ij. Specimens were observed under a light microscope (DM4000B with a plan $40 \times$ objective, aperture $0.65,10 \times$ ocular; Leica Microsystems, Wetzlar, Germany), and images of representative fields were captured with a digital camera (DFC480; Leica Microsystems) onto a hard drive disk and then opened with the Image J software to evaluate the indices of positive staining that was regarded as Labeling Index (LI). With the aim to use the cell counter technique, positive and negative stained cells were marked placing different colors marks by mouse clicking directly from the screen. For each case a minimum of $10^{3}$ cells was counted; ImageJ software was then able to automatically generate the percentage of tumor cells stained with HPV16 E7 and HIF-1 $\alpha$ antibodies. Only epithelial cells were counted 
regardless of localization or intensity of staining. Twenty random cases were evaluated separately by two different observers (V.R. and F.A.); since the variation was less than $5 \%$, the first pathologist's data were used.

\section{Statistical methods}

Continuous variables were analyzed as mean values \pm standard deviation (SD). Rates and proportions were calculated for categorical data. For categorical variables, differences were analyzed by the $\chi^{2}$ test and Fisher exact test when appropriate. Normality of distribution for quantitative data was assessed by the Kolmogorov-Smirnov test. Differences between two groups were detected by the unpaired Student's t-test for continuous variables with normal distribution. For continuous variable without normal distribution, we used nonparametric tests, and differences were analyzed by the Mann-Whitney $U$ test. Correlations among continuous variables were determined by the use of Spearman test. $p<.05$ was considered statistically significant. All analyses were performed with Statistical Package for Social Science (SPSS for Windows, version 17.0; $\odot$ SPSS Inc., Chicago, Ill, USA).

\section{List of abbreviations}

HR: High Risk; HPV: Human PapillomaVirus; OSCC: Oral Squamous Cell Carcinoma; HIF-1a: Hypoxia Inducible Factor-1 alpha; HDAC: Histone DeACetylases; HIF-1B: Hypoxia Inducible Factor-1 beta; VHL: Von HippelLindau; CBP: CREB Binding Protein; SCC: Squamous Cell Carcinoma; PCNA: Proliferating Cell Nuclear Antigen; DFO: DeFeroxamine Mesylate; PCR: Polymerase Chain Reaction; IRB: Institutional Review Board; HG: Histological Grading; nPCR: Nested Polymerase Chain Reaction; LI: Labeling Index; NIH: National Institutes of Health; SD: standard deviation; SPSS: Statistical Package for Social Science.

\section{Acknowledgements}

This work was supported by grants from the Ministero dell'Istruzione dell'Università e della Ricerca (MIUR - PRIN 2088 CUP B71J1000008001).

\section{Author details}

'Department of Sciences for Health Promotion, Section of Anatomic Pathology, University of Palermo, Palermo, Italy. ${ }^{2}$ Department of Biomedical Internal and Specialized Medicine, Section of Endocrinology, University of Palermo, Palermo, Italy. ${ }^{3}$ Department of Experimental Medicine and Clinical Neuroscience, University of Palermo, Palermo, Italy. ${ }^{4}$ Department of Surgical and Oncologic Disciplines, Section of Oral Medicine, University of Palermo, Palermo, Italy. ${ }^{5}$ Department of Surgical Sciences, Section of Anatomic Pathology and Cytopathology, University of Foggia, Foggia, Italy.

\footnotetext{
Authors' contributions

VR and GC: were responsible for developing the concept, full proposal development and obtaining ethical approvals. ODF: carried out the field work and was responsible for data collection. WA and FA: made all laboratory analyses and contributed to the interpretation of laboratory results. VR: analyzed the labeling indexes. MCA: provided statistical analyses and interpretation of the results. WA: wrote the manuscript while VR GC FC and GP: gave their critical comments upon the writing process and revised the final manuscript. All authors read and approved the version to be published.
}

\section{Competing interests}

The authors declare that they have no competing interests.
Received: 23 September 2011 Accepted: 27 October 2011

Published: 27 October 2011

\section{References}

1. Smith EM, Ritchie $J M$, Summersgill KF, Hoffman $H T$, Wang $D H$, Haugen $T H$, Turek LP: Human papillomavirus in oral exfoliated cells and risk of head and neck cancer. J Natl Cancer Inst 2004, 96:449-455.

2. Gillison ML, Koch WM, Capone RB, Spafford M, Westra WH, Wu L, Zahurak ML, Daniel RW, Viglione M, Symer DE, et al: Evidence for a causal association between human papillomavirus and a subset of head and neck cancers. J Natl Cancer Inst 2000, 92:709-720.

3. Gillison ML, Koch WM, Shah KV: Human papillomavirus in head and neck squamous cell carcinoma: are some head and neck cancers a sexually transmitted disease? Curr Opin Oncol 1999, 11:191-199.

4. Gillison ML, Shah KV: Human papillomavirus-associated head and neck squamous cell carcinoma: mounting evidence for an etiologic role for human papillomavirus in a subset of head and neck cancers. Curr Opin Oncol 2001, 13:183-188.

5. Mork J, Lie AK, Glattre E, Hallmans G, Jellum E, Koskela P, Moller B, Pukkala E, Schiller JT, Youngman L, et al: Human papillomavirus infection as a risk factor for squamous-cell carcinoma of the head and neck. $N$ Engl J Med 2001, 344:1125-1131.

6. Smith EM, Hoffman HT, Summersgill KS, Kirchner HL, Turek LP, Haugen TH: Human papillomavirus and risk of oral cancer. Laryngoscope 1998, 108:1098-1103.

7. Smith EM, Ritchie JM, Summersgill KF, Klussmann JP, Lee JH, Wang D, Haugen TH, Turek LP: Age, sexual behavior and human papillomavirus infection in oral cavity and oropharyngeal cancers. Int J Cancer 2004, 108:766-772.

8. Lindel K, Beer KT, Laissue J, Greiner RH, Aebersold DM: Human papillomavirus positive squamous cell carcinoma of the oropharynx: a radiosensitive subgroup of head and neck carcinoma. Cancer 2001, 92:805-813.

9. Schwartz SM, Daling JR, Doody DR, Wipf GC, Carter JJ, Madeleine MM, Mao EJ, Fitzgibbons ED, Huang S, Beckmann AM, et al: Oral cancer risk in relation to sexual history and evidence of human papillomavirus infection. J Natl Cancer Inst 1998, 90:1626-1636.

10. Schwartz SR, Yueh B, McDougall JK, Daling JR, Schwartz SM: Human papillomavirus infection and survival in oral squamous cell cancer: a population-based study. Otolaryngol Head Neck Surg 2001, 125:1-9.

11. Sisk EA, Bradford CR, Jacob A, Yian CH, Staton KM, Tang G, Harris MO, Carey TE, Lancaster WD, Gregoire L: Human papillomavirus infection in "young" versus "old" patients with squamous cell carcinoma of the head and neck. Head Neck 2000, 22:649-657.

12. Castellsague X, Bosch FX, Munoz N: Environmental co-factors in HPV carcinogenesis. Virus Res 2002, 89:191-199.

13. Chang JY, Lin MC, Chiang CP: High-risk human papillomaviruses may have an important role in non-oral habits-associated oral squamous cell carcinomas in Taiwan. Am J Clin Pathol 2003, 120:909-916.

14. Dahlstrom KR, Adler-Storthz K, Etzel CJ, Liu Z, Dillon L, El-Naggar AK, Spitz MR, Schiller JT, Wei Q, Sturgis EM: Human papillomavirus type 16 infection and squamous cell carcinoma of the head and neck in neversmokers: a matched pair analysis. Clin Cancer Res 2003, 9:2620-2626.

15. de Villiers EM, Gunst K, Stein H, Scherubl H: Esophageal squamous cell cancer in patients with head and neck cancer: Prevalence of human papillomavirus DNA sequences. Int I Cancer 2004, 109:253-258.

16. Herrero R, Castellsague X, Pawlita M, Lissowska J, Kee F, Balaram P, Rajkumar T, Sridhar H, Rose B, Pintos J, et al: Human papillomavirus and oral cancer: the International Agency for Research on Cancer multicenter study. J Natl Cancer Inst 2003, 95:1772-1783.

17. Clifford GM, Smith JS, Plummer M, Munoz N, Franceschi S: Human papillomavirus types in invasive cervical cancer worldwide: a metaanalysis. Br J Cancer 2003, 88:63-73.

18. Walboomers JM, Jacobs MV, Manos MM, Bosch FX, Kummer JA, Shah KV, Snijders PJ, Peto J, Meijer CJ, Munoz N: Human papillomavirus is a necessary cause of invasive cervical cancer worldwide. J Pathol 1999, 189:12-19

19. Kreimer AR, Clifford GM, Boyle P, Franceschi S: Human papillomavirus types in head and neck squamous cell carcinomas worldwide: a systematic review. Cancer Epidemiol Biomarkers Prev 2005, 14:467-475. 
20. Termine N, Panzarella V, Falaschini S, Russo A, Matranga D, Lo Muzio L, Campisi G: HPV in oral squamous cell carcinoma vs head and neck squamous cell carcinoma biopsies: a meta-analysis (1988-2007). Ann Oncol 2008, 19:1681-1690.

21. Azzimonti B, Pagano M, Mondini M, De Andrea M, Valente G, Monga G, Tommasino M, Aluffi P, Landolfo S, Gariglio M: Altered patterns of the interferon-inducible gene IFI16 expression in head and neck squamous cell carcinoma: immunohistochemical study including correlation with retinoblastoma protein, human papillomavirus infection and proliferation index. Histopathology 2004, 45:560-572.

22. Dai M, Clifford GM, le Calvez F, Castellsague X, Snijders PJ, Pawlita M, Herrero R, Hainaut P, Franceschi S: Human papillomavirus type 16 and TP53 mutation in oral cancer: matched analysis of the IARC multicenter study. Cancer Res 2004, 64:468-471.

23. Munger $K$, Baldwin A, Edwards KM, Hayakawa H, Nguyen $C L$, Owens M, Grace M, Huh K: Mechanisms of human papillomavirus-induced oncogenesis. J Virol 2004, 78:11451-11460.

24. Bodily JM, Mehta KP, Laimins LA: Human papillomavirus E7 enhances hypoxia-inducible factor 1-mediated transcription by inhibiting binding of histone deacetylases. Cancer Research 2011, 71:1187-1195.

25. Hanahan D, Folkman J: Patterns and emerging mechanisms of the angiogenic switch during tumorigenesis. Cell 1996, 86:353-364.

26. Brat DJ, Kaur B, Van Meir EG: Genetic modulation of hypoxia induced gene expression and angiogenesis: relevance to brain tumors. Front Biosci 2003, 8:d100-116.

27. Bardos Jl, Ashcroft M: Negative and positive regulation of HIF-1: a complex network. Biochim Biophys Acta 2005, 1755:107-120.

28. Ruas $J$, Poellinger L: Hypoxia-dependent activation of HIF into a transcriptional regulator. Semin Cell Dev Biol 2005, 16:514-522.

29. Schmid T, Zhou J, Brune B: HIF-1 and p53: communication of transcription factors under hypoxia. J Cell Mol Med 2004, 8:423-431.

30. Ruas JL, Berchner-Pfannschmidt U, Malik S, Gradin K, Fandrey J, Roeder RG, Pereira $T$, Poellinger $L$ : Complex regulation of the transactivation function of hypoxia-inducible factor-1 alpha by direct interaction with two distinct domains of the CREB-binding protein/p300. J Biol Chem 2010, 285:2601-2609.

31. Chang CC, Lin BR, Chen ST, Hsieh TH, Li YJ, Kuo MY: HDAC2 promotes cell migration/invasion abilities through HIF-1alpha stabilization in human oral squamous cell carcinoma. J Oral Pathol Med 2011, 40:567-575.

32. Bodily JM, Mehta KP, Laimins LA: Human papillomavirus E7 enhances hypoxia-inducible factor 1-mediated transcription by inhibiting binding of histone deacetylases. Cancer Res 2011, 71:1187-1195.

33. Fiedler M, Muller-Holzner E, Viertler HP, Widschwendter A, Laich A, Pfister G, Spoden GA, Jansen-Durr P, Zwerschke W: High level HPV-16 E7 oncoprotein expression correlates with reduced pRb-levels in cervical biopsies. Faseb J 2004, 18:1120-1122.

34. Ha PK, Califano JA: The role of human papillomavirus in oral carcinogenesis. Crit Rev Oral Biol Med 2004, 15:188-196.

35. Fakhry C, Westra WH, Li S, Cmelak A, Ridge JA, Pinto H, Forastiere A Gillison ML: Improved survival of patients with human papillomaviruspositive head and neck squamous cell carcinoma in a prospective clinical trial. J Natl Cancer Inst 2008, 100:261-269.

36. Li W, Thompson CH, O'Brien CJ, MCNeil EB, Scolyer RA, Cossart YE, Veness MJ, Walker DM, Morgan GJ, Rose BR: Human papillomavirus positivity predicts favourable outcome for squamous carcinoma of the tonsil. Int J Cancer 2003, 106:553-558.

37. Mellin H, Friesland S, Lewensohn R, Dalianis T, Munck-Wikland E: Human papillomavirus (HPV) DNA in tonsillar cancer: clinical correlates, risk of relapse, and survival. Int J Cancer 2000, 89:300-304.

38. Soares CP, Benatti Neto C, Fregonezi PA, Teresa DB, Santos RT, Longatto Filho A, Maeda MY: Computer-assisted analysis of p53 and PCNA expression in oral lesions infected with human papillomavirus. Anal Quant Cytol Histol 2003, 25:19-24

39. Richardson $H$, Kelsall G, Tellier P, Voyer $H$, Abrahamowicz M, Ferenczy A, Coutlee F, Franco EL: The natural history of type-specific human papillomavirus infections in female university students. Cancer Epidemiol Biomarkers Prev 2003, 12:485-490.

40. Stanley M: Immunobiology of HPV and HPV vaccines. Gynecol Oncol 2008, 109:S15-21.
41. Park RB, Androphy EJ: Genetic analysis of high-risk e6 in episomal maintenance of human papillomavirus genomes in primary human keratinocytes. J Virol 2002, 76:11359-11364.

42. Thomas M, Pim D, Banks L: The role of the E6-p53 interaction in the molecular pathogenesis of HPV. Oncogene 1999, 18:7690-7700.

43. Kadaja M, Isok-Paas H, Laos T, Ustav E, Ustav M: Mechanism of genomic instability in cells infected with the high-risk human papillomaviruses. PLoS Pathogens 2009, 5:e1000397.

44. zur Hausen H: Papillomaviruses and cancer: from basic studies to clinical application. Nature Reviews Cancer 2002, 2:342-350.

45. Hanahan D, Weinberg RA: The hallmarks of cancer. Cell 2000, 100:57-70.

46. Smith-McCune K, Zhu YH, Hanahan D, Arbeit J: Cross-species comparison of angiogenesis during the premalignant stages of squamous carcinogenesis in the human cervix and K14-HPV16 transgenic mice. Cancer Res 1997, 57:1294-1300.

47. Smith-McCune KK, Weidner N: Demonstration and characterization of the angiogenic properties of cervical dysplasia. Cancer Res 1994, 54:800-804.

48. Tang X, Zhang Q, Nishitani J, Brown J, Shi S, Le AD: Overexpression of human papillomavirus type 16 oncoproteins enhances hypoxia-inducible factor 1 alpha protein accumulation and vascular endothelial growth factor expression in human cervical carcinoma cells. Clin Cancer Res 2007, 13:2568-2576.

49. Clere N, Bermont L, Fauconnet S, Lascombe I, Saunier M, Vettoretti L, Plissonnier ML, Mougin C: The human papillomavirus type $18 \mathrm{E} 6$ oncoprotein induces Vascular Endothelial Growth Factor 121 (VEGF121) transcription from the promoter through a p53-independent mechanism. Exp Cell Res 2007, 313:3239-3250.

50. Chen W, Li F, Mead L, White H, Walker J, Ingram DA, Roman A: Human papillomavirus causes an angiogenic switch in keratinocytes which is sufficient to alter endothelial cell behavior. Virology 2007, 367:168-174.

51. Toussaint-Smith E, Donner DB, Roman A: Expression of human papillomavirus type 16 E6 and E7 oncoproteins in primary foreskin keratinocytes is sufficient to alter the expression of angiogenic factors. Oncogene 2004, 23:2988-2995.

52. Nakamura M, Bodily JM, Beglin M, Kyo S, Inoue M, Laimins LA: Hypoxiaspecific stabilization of HIF-1alpha by human papillomaviruses. Virology 2009, 387:442-448

53. Campisi G, Giovannelli L, Calvino F, Matranga D, Colella G, Di Liberto C, Capra G, Leao JC, Lo Muzio L, Capogreco M, D'Angelo M: HPV infection in relation to OSCC histological grading and TNM stage. Evaluation by traditional statistics and fuzzy logic model. Oral Oncol 2006, 42:638-645.

54. Barnes LEJ, Reichart P, Sidransky D: Head and Neck Tumours. Pathology and Genetics. WHO Classification of Tumours Lyon: IARC Press; 2005.

55. Pikor LA, Enfield KS, Cameron H, Lam WL: DNA extraction from paraffin embedded material for genetic and epigenetic analyses. J Vis Exp 2011, (49).

56. Giovannelli L, Campisi G, Lama A, Giambalvo O, Osborn J, Margiotta V Ammatuna P: Human papillomavirus DNA in oral mucosal lesions. J Infect Dis 2002, 185:833-836.

57. Zerilli M, Zito G, Martorana A, Pitrone M, Cabibi D, Cappello F, Giordano C, Rodolico V: BRAF(V600E) mutation influences hypoxia-inducible factor1alpha expression levels in papillary thyroid cancer. Mod Pathol 2010, 23:1052-1060.

\section{doi:10.1186/1750-9378-6-18}

Cite this article as: Rodolico et al:: Hypoxia inducible factor-1 alpha expression is increased in infected positive HPV16 DNA oral squamous cell carcinoma and positively associated with HPV16 E7 oncoprotein. Infectious Agents and Cancer 2011 6:18. 